\title{
LODO DE ESGOTO E CAMA DE AVIÁRIO COMO COMPONENTE DE SUBSTRATOS PARA A PRODUÇÃO DE MUDAS DE Cedrela fissilis E Anadenanthera macrocarpa (BENTH). BRENAN
}

\author{
Sewage sludge and broiler litter component of substrates for seedling production Cedrela fissilis e Anadenanthera \\ macrocarpa (Benth). Brenan
}

\author{
Joseane Bortolini ${ }^{1 *}$; Dinéia Tessaro ${ }^{2 *}$; Morgana Suszek Gonçalves ${ }^{3}$; Sheila Regina Oro ${ }^{4}$ \\ ${ }^{1}$ Professora MsC; Centro Universitário da Fundação Assis Gurgacz - Campus Cascavel; e-mail: josi_bortolini@hotmail.com \\ *Autor para correspondência \\ 2Professora Dr.; Universidade Tecnológica Federal do Paraná - Campus Dois Vizinhos; e-mail: dtessaro@utfpr.edu.br \\ *Autor para correspondência \\ 3Professora Dr.; Universidade Tecnológica Federal do Paraná - Campus Campo Mourão; e-mail:morgana@utfpr.edu.br \\ 4Professora Dr.; Universidade Tecnológica Federal do Paraná - Campus Francisco Beltrão; e-mail:sheilaro@utfpr.edu.br
}

Artigo enviado em 04/07/2017, aceito em 10/09/2017 e publicado em 20/12/2017.

\begin{abstract}
Resumo: O objetivo do trabalho foi testar doses de lodo de esgoto e cama de aviário associada ao substrato comercial em diferentes proporções para a produção de mudas de Cedrela fissilis e Anadenanthera macrocarpa (Benth). Brenan. O estudo foi desenvolvido em casa de vegetação, e os tratamentos testados foram: T0: $100 \%$ substrato; T1: $75 \%$ substrato $+25 \%$ cama de aviário; T2: 50\% substrato $+50 \%$ cama de aviário; T3: $75 \%$ substrato $+25 \%$ lodo de esgoto; T4: $50 \%$ substrato $+50 \%$ lodo de esgoto. As plantas de cada tratamento foram avaliadas aos 30, 60 e 90 dias após replantio quanto aos parâmetros fitométricos: comprimento de raiz, comprimento da parte aérea, número de folhas, massa seca de raiz, massa seca de parte aérea, diâmetro do coleto, massa fresca da parte aérea e, massa fresca da raiz. $\mathrm{O}$ uso da cama de aviário na produção das mudas não foi eficiente, uma vez que as plantas, nos tratamentos T1 e T2, não sobreviveram. Os tratamentos T3 e T4, compostos por diferentes proporções de lodo, apresentaram efeitos positivos significativos sobre o parâmetro comprimento da parte aérea aos 30 dias após replantio para as mudas de Angico. Os demais parâmetros não apresentaram diferenças estatísticas significativas em relação ao substrato comercial em nenhuma das avaliações para ambas as espécies. Contudo, observou-se tendência positiva no tratamento T3 aos 90 dias após o replantio para todos os parâmetros, evidenciando a possibilidade do reaproveitamento do lodo na produção de mudas de Cedrela fissilis e Anadenanthera macrocarpa (Benth).
\end{abstract}

Palavras-chave - biossólido, composto orgânico, parâmetros fitométricos.

Abstract: The objective of this work was to test the doses of sewage sludge and broiler litter associated with the commercial substrate in different proportions for the production of seedlings Cedrela fissilis and Anadenanthera macrocarpa (Benth). Brenan. The study was carried out in house with vegetation, and the treatments tested were: T0: 100\% substrate; T1: $75 \%$ substrate $+25 \%$ broiler litter; T2: 50\% substrate $+50 \%$ broiler litter; T3: $75 \%$ substrate + $25 \%$ sewage sludge; T4: $50 \%$ substrate $+50 \%$ sewage sludge. The plants of each treatment were evaluated at 30,60 and 90 days after replanting for the phytometric parameters: root length, shoot length, leaf number, root dry mass, shoot dry mass, collection diameter, mass Fresh aerial part and, fresh root pasta. The use of the broiler litter in the production of the seedlings was not efficient, since the plants, in the treatments T1 and T2, did not survive. The treatments T3 and T4, composed of different proportions of sludge, had significant positive effects on the length parameter of the area at 30 days after replanting for the Angico seedlings. The other parameters did not present significant statistical differences in relation to the commercial substrate in any of the evaluations for both species. However, a positive trend was observed in $\mathrm{T} 3$ treatment at 90 days after replanting for all parameters, evidencing the possibility of reuse of the sludge in the production of Cedrela fissilis and Anadenanthera macrocarpa (Benth) seedlings.

Keywords - biosolids, organic compost, phytometric parameters. 


\section{INTRODUÇÃO}

A qualidade de mudas florestais está diretamente ligada ao substrato em que estas são produzidas. Mudas de qualidade são fundamentais para implantação de projetos florestais, influenciando diretamente o sucesso da produtividade da floresta (TRAZZI et al., 2012). Essa qualidade pode ser alcançada pelo uso de fertilizantes orgânicos de várias origens, destacando-se os compostos formulados a partir de estercos animais e lodo de esgoto, capazes de promover melhorias nas características físicas, químicas e biológicas do solo, além de minimizar o uso de fertilizantes químicos (KIEHL, 1985).

A diversidade de substratos disponíveis é grande, podendo ser encontrados diversos tipos prontos para o uso, com características próprias de preço e qualidade. No entanto, o uso de um único material dificilmente atenderá a todas as necessidades para a produção de mudas, sendo comum a combinação de dois ou mais materiais para obtenção de um substrato de qualidade que atenda todas as necessidades da planta (LIMA et al., 2009; CALDEIRA et al., 2011a).

Considera-se como função primordial do substrato prover o suporte físico e nutricional das plantas. Por meio de sua fase sólida, o substrato influi na manutenção do sistema radicular da planta, suprimento de água e nutrientes, enquanto a fase líquida atua no suprimento de oxigênio e transporte de carbono entre as raízes e o ar externo pela fase gasosa, melhorando a relação água/ar e a disponibilidade de nutrientes. Além disso, os fatores $\mathrm{pH}$, capacidade de troca catiônica, salinidade e teor de matéria orgânica são as principais características químicas a serem consideradas (SCHMITZ; SOUZA; KÄMPF, 2002; CALDEIRA et al., 2011b).

A matéria orgânica favorece $O$ desenvolvimento de micro-organismos benéficos, aumentando, consequentemente a disponibilidade de nutrientes ao longo do período da produção das mudas, eleva o $\mathrm{pH}$ e a capacidade de troca de cátions, além de aumentar a capacidade de retenção de água (TRAZZI; CALDEIRA; COLOMBI, 2010; CALDEIRA et al., 2011b; TRIGUEIRO; GUERRINI, 2003).

Nesse sentido, pesquisas relacionadas com o uso de materiais orgânicos, como os resíduos agroindustriais e urbanos, como a cama de aviário e o lodo de esgoto são alternativas viáveis para uso como mistura na produção de substrato, pois grandes volumes destes produtos são gerados e representam um problema ambiental quanto a destinação apropriada (CALDEIRA et al, 2014). Portanto, a utilização desses resíduos como componente do substrato, além de propiciar economia na produção de mudas, garante destino apropriado para os mesmos, evitando que seu acúmulo torne-se um problema ambiental. Esta preocupação é ainda mais pertinente considerando que o país é um dos maiores produtores e exportador de frangos do mundo (CARDOSO et al., 2009) e que o lodo gerado nas estações de tratamento de esgoto apresenta sérias restrições de uso, em virtude de seu potencial poluidor, sendo destinado a aterros sanitários, o que limita a reciclagem e reaproveitamento do resíduo (GOMES et al., 2013).

Embora esta potencialidade exista, as respostas quanto a sua efetividade ainda são restritas no âmbito da produção de mudas de espécies arbóreas nativas. As principais lacunas a serem preenchidas referem-se aos potenciais fertilizantes de cada resíduo sólido, bem como das melhores dosagens para a obtenção de resultados satisfatórios. Considerando esta preocupação, é necessária a realização de estudos que avaliem a utilização de diferentes resíduos e dosagens em diferentes espécies nativas e seus efeitos sobre o crescimento.

Diante deste cenário, o trabalho, objetivou avaliar o efeito de diferentes proporções de lodo de esgoto, cama de aviário e substrato comercial sobre as características de crescimento de mudas de Anadenanthera macrocarpa (Benth). Brenan e Cedrela fissilis, a fim de obter um meio de crescimento adequado para tais espécies florestais.

\section{MATERIAL E MÉTODOS}

\section{Descrição da área de estudo}

O experimento foi conduzido em casa de vegetação no Viveiro Municipal, localizado no município de Francisco Beltrão-PR. As mudas utilizadas para o estudo foram disponibilizadas pelo viveiro, sendo selecionadas entre as espécies arbóreas nativas da região, a Cedrela fissilis popularmente conhecida como Cedro e Anadenanthera macrocarpa (Benth.) Brenan, conhecida como Angico.

Os compostos utilizados foram preparados pela mistura de substrato comercial com diferentes doses de cama de aviário e lodo de esgoto. O resíduo de cama de aviário utilizado foi coletado em uma granja próxima a Francisco Beltrão, utilizando a cama de aviário in natura oriunda do décimo segundo lote. O lodo de esgoto foi cedido pela Companhia de Saneamento do Paraná (SANEPAR) de Francisco 
Beltrão, sendo o lodo tratado nas etapas de gradeamento, desarenador, reator anaeróbio de lodo fluidizado (RALF), filtro biológico (camada filme de micro-organismos), leito de secagem, e calagem para estabilização e desinfecção do lodo.

A cama de aves, lodo de esgoto e substrato comercial foram caracterizados quimicamente (Tabela 1), segundo metodologia da ABNT.

Tabela 1. Caracterização química dos resíduos de cama de aviário e lodo de esgoto.

\begin{tabular}{lccc}
\hline Parâmetros & $\mathrm{CA}$ & $\mathrm{LE}$ & $\mathrm{SC}$ \\
\hline $\mathrm{pH}$ & 8,9 & 7,5 & 5,6 \\
Umidade (\%) & 26,8 & 10,2 & 10,2 \\
$\mathrm{CO}(\%)$ & 36,9 & 9,7 & 19,2 \\
$\mathrm{MO}(\%)$ & 63,4 & 16,7 & 33,0 \\
$\mathrm{~N}(\%)$ & 1,9 & 1,2 & 0,6 \\
$\mathrm{P}_{2} \mathrm{O} 5(\%)$ & 1,7 & 0,7 & 1,0 \\
$\mathrm{~K} 2 \mathrm{O}(\%)$ & 3,4 & 0,1 & 0,4 \\
$\mathrm{Ca}(\%)$ & 2,8 & 5,3 & 2,6 \\
$\mathrm{Mg}(\%)$ & 0,7 & 0,3 & 0,7 \\
$\mathrm{~S}(\%)$ & 0,5 & 0,8 & 0,3 \\
$\mathrm{Boro}\left(\mathrm{mg} \mathrm{kg}^{-1}\right)$ & 55,0 & 24,0 & 34,0 \\
$\mathrm{Cu}\left(\mathrm{mg} \mathrm{kg}^{-1}\right)$ & 416,0 & 114,0 & 53,0 \\
$\mathrm{Mn}\left(\mathrm{mg} \mathrm{kg}^{-1}\right)$ & 382,0 & 222,0 & 257,0 \\
$\mathrm{Zn}\left(\mathrm{mg} \mathrm{kg}^{-1}\right)$ & 300,0 & 283,0 & 63,0 \\
$\mathrm{Fe}\left(\mathrm{mg} \mathrm{kg}^{-1}\right)$ & 7027,0 & 7519,0 & 1000,0 \\
$\mathrm{Relação} \mathrm{C} / \mathrm{N}$ & $19,5 / 1$ & $8,2 / 1$ & $30,4 / 1$ \\
\hline CA: cama de aviário; LE: Lodo de esgoto; SC: Substrato comercial.
\end{tabular}

As proporções de lodo e cama de aviário totalizaram 5 tratamentos para cada espécie avaliada, sendo: T0: $100 \%$ substrato; T1: $75 \%$ substrato $+25 \%$ cama de aviário; T2: 50\% substrato $+50 \%$ cama de aviário; T3: $75 \%$ substrato $+25 \%$ lodo de esgoto; T4: $50 \%$. substrato $+50 \%$ lodo de esgoto.

Para o preparo das diferentes proporções de substratos e resíduos, os mesmos foram peneirados em malha de $9 \mathrm{~mm}$ e, então misturados nas porcentagens correspondentes aos tratamentos. Em seguida, os sacos plásticos para o plantio das mudas $(10 \mathrm{~cm} \times 20 \mathrm{~cm})$ foram preenchidos de acordo com cada tratamento, sendo então realizada a transferência das mudas. Foram utilizadas mudas com 30 dias de cada uma das espécies. Após a transferência das mudas, as mesmas foram mantidas e acompanhadas diariamente em casa de vegetação a qual contava com sistema de irrigação automática quatro vezes ao dia.

Aos 30, 60 e 90 dias após o replantio das mudas nos respectivos tratamentos, foram selecionadas aleatoriamente, cinco plantas de cada tratamento. Os parâmetros fitométricos analisados foram: Comprimento de Raiz (CR), Comprimento da
Parte Aérea (CPA), Número de Folhas (NF), Massa Seca de Raiz (MSR), Massa Seca de Parte Aérea (MSPA) e Diâmetro do Coleto (DC).

A determinação dos parâmetros comprimento de raiz e comprimento da parte aérea foram realizados com auxílio de régua graduada $\mathrm{em}$ milímetros. O número de folhas foi verificado por contagem, enquanto que o diâmetro do coleto foi determinado com paquímetro calibrado. Após a mensuração destes parâmetros, as plantas foram separadas em parte aérea e raiz, as quais foram acondicionadas individualmente em sacos de papel Kraft e secas em estufa de circulação de ar, a $60^{\circ} \mathrm{C}$, até peso constante, com posterior pesagem em balança de precisão para determinação da massa seca da raiz e massa seca da parte aérea.

Para a realização das análises estatísticas foram considerados apenas os dados referentes aos tratamentos T0, T3 e T4, uma vez que as mudas nos tratamentos T1 e T2 não sobreviveram durante $\mathrm{o}$ decorrer do experimento. Os parâmetros fitométricos para cada uma das espécies estudadas foram analisados estatisticamente segundo delineamento inteiramente casualizado com três tratamentos e cinco repetições, sendo realizada comparação entre médias pelo Teste de Tukey, ao nível de $5 \%$ de significância, utilizando o software livre SISVAR, versão 4.6.

\section{RESULTADOS E DISCUSSÃO}

Todo o experimento foi conduzido em casa de vegetação, controlando as condições necessárias para o desenvolvimento das espécies. No entanto, 7 dias após o replantio das mudas, nos respectivos tratamentos, foi verificada a morte de todas as plantas no tratamento $\mathrm{T} 2(50 \%$ substrato $+50 \%$ cama de aviário) para as duas espécies avaliadas. Buscando verificar o motivo da morte das plantas, realizou-se nova mistura do substrato e da cama de aviário nas proporções citadas, procedendo-se novo replantio. No entanto, o resultado obtido foi o mesmo. Aos 15 dias após o replantio foram verificados resultados similares no tratamento $\mathrm{T} 1(25 \%$ cama de aviário + $75 \%$ substrato), ocorrendo à morte das mudas de angico, enquanto as de cedro sobreviveram.

Tais resultados, são similares aos descritos por Carvalho et al. (2004), os quais testaram dosagens crescentes de cama de aviário no desenvolvimento de mudas de Abieiro, nas proporções de $0 \%, 10 \%, 20 \%$, $30 \%, 40 \%$ e $50 \%$ em mistura com terriço retirado da camada de $0-20 \mathrm{~cm}$ de um Latossolo Amarelo. Os autores observaram que a adição de cama de aviário propiciou aumento no crescimento das mudas nas 
doses de $10 \%$ e $20 \%$, e morte ou redução do crescimento nas doses superiores. Desta forma, os autores concluíram que a cama de aviário, como fonte de nutrientes, na formulação de substrato para a produção de mudas, não deve exceder a proporção de $10 \%$ a $20 \%$ da mistura, evitando efeito tóxico e, obtendo-se desta forma, a máxima produção da plântula, em matéria seca. Brugnara (2014), estudando o uso de cama de aves na produção de mudas de maracujá, observou mortalidade de plantas ou ausência de emergência utilizando cama de aves seca ao ar na proporção de $40 \%$ cama de aves e $60 \%$ de material base, composto por solo ou substrato comercial.

De acordo com os resultados apresentados na Tabela 1 , verifica-se que a relação $\mathrm{C} / \mathrm{N}$ para a cama de aviário foi de 19,5/1. De acordo com Paulus, Muller e Barcellos (2000) a relação $\mathrm{C} / \mathrm{N}$ de um composto estabilizado, pronto para ser utilizado como adubo, deve ser menor que 18/1. Contudo, o composto é considerado humificado ou completamente curado, quando apresenta relação C/N em torno de 10/1 (KIEHL, 1985; HUANG et al., 2004), indicando que possivelmente a cama de aviário utilizada não estava totalmente estabilizada, interferindo na sobrevivência das mudas. Qi et al. (2012), destacam ainda, que a volatilização de $\mathrm{N}$ na forma de amônia presente em elevada quantidade na cama de aves pode reduzir o crescimento das plantas.

Considerando a morte prematura das mudas nos tratamentos com cama de aviário, tais tratamentos foram descartados, considerando-se para o prosseguimento do estudo apenas os tratamentos: T0: $100 \%$ substrato, T3: $25 \%$ lodo de esgoto $+75 \%$ substrato e T4: 50\% lodo de esgoto $+50 \%$ substrato, para ambas as espécies nativas. $\mathrm{Na}$ Tabela 2, são apresentados os resultados obtidos, aos 30, 60 e 90 dias após o replantio, quanto aos parâmetros fitométricos para as mudas de Angico e Cedro.

Tabela 2. Valores médios dos parâmetros fitométricos analisados para as mudas de Angico e Cedro aos 30, 60 e 90 dias após o replantio.

\begin{tabular}{|c|c|c|c|c|c|c|c|}
\hline \multicolumn{8}{|c|}{ Angico } \\
\hline & Tratamento & $\mathrm{CR}(\mathrm{cm})$ & $\mathrm{CPA}(\mathrm{cm})$ & $\mathrm{NF}$ & $\mathrm{DC}(\mathrm{mm})$ & $\operatorname{MSR}(g)$ & $\operatorname{MSPA}(\mathrm{g})$ \\
\hline \multirow{3}{*}{ চి. } & T0 & $8,44 \mathrm{a}$ & $4,00 \mathrm{a}$ & $6,00 \mathrm{a}$ & $1,0 \mathrm{a}$ & $0,02 \mathrm{a}$ & $0,06 \mathrm{a}$ \\
\hline & T3 & $6,84 \mathrm{a}$ & $6,18 \mathrm{~b}$ & $3,60 \mathrm{a}$ & $1,0 \mathrm{a}$ & $0,01 \mathrm{a}$ & $0,05 \mathrm{a}$ \\
\hline & $\mathrm{T} 4$ & $7,30 \mathrm{a}$ & $6,56 \mathrm{~b}$ & $3,60 \mathrm{a}$ & $1,0 \mathrm{a}$ & $0,01 \mathrm{a}$ & $0,05 \mathrm{a}$ \\
\hline \multirow{3}{*}{$8 . \stackrel{乛}{0}$} & T0 & $17,54 \mathrm{a}$ & $16,50 \mathrm{a}$ & $14,40 \mathrm{a}$ & $1,8 \mathrm{a}$ & $0,06 \mathrm{a}$ & $0,19 \mathrm{a}$ \\
\hline & T3 & $16,50 \mathrm{a}$ & $13,70 \mathrm{a}$ & $11,60 \mathrm{a}$ & $1,2 \mathrm{a}$ & $0,05 \mathrm{a}$ & $0,14 \mathrm{a}$ \\
\hline & T4 & $13,00 \mathrm{a}$ & $14,30 \mathrm{a}$ & $13,80 \mathrm{a}$ & $1,4 \mathrm{a}$ & 0,06 a & 0,18 a \\
\hline \multirow{3}{*}{ 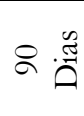 } & T0 & $20,00 \mathrm{a}$ & $29,8 \mathrm{a}$ & $34,4 \mathrm{a}$ & $2,2 \mathrm{a}$ & $0,15 \mathrm{a}$ & $0,62 \mathrm{a}$ \\
\hline & T3 & $21,60 \mathrm{a}$ & $34,3 \mathrm{a}$ & $42,2 \mathrm{a}$ & $2,4 \mathrm{a}$ & $0,28 \mathrm{a}$ & $0,87 \mathrm{a}$ \\
\hline & $\mathrm{T} 4$ & $18,60 \mathrm{a}$ & $28,0 \mathrm{a}$ & $33,2 \mathrm{a}$ & $2,4 \mathrm{a}$ & $0,19 \mathrm{a}$ & $0,80 \mathrm{a}$ \\
\hline \multicolumn{8}{|c|}{ Cedro } \\
\hline \multirow{3}{*}{ ๙ } & T0 & $7,96 \mathrm{a}$ & $5,92 \mathrm{a}$ & $4,00 \mathrm{a}$ & $1,7 \mathrm{a}$ & $0,03 \mathrm{a}$ & $0,07 \mathrm{a}$ \\
\hline & T3 & $5,22 \mathrm{a}$ & $5,82 \mathrm{a}$ & $4,20 \mathrm{a}$ & $1,4 \mathrm{a}$ & $0,02 \mathrm{a}$ & $0,04 \mathrm{a}$ \\
\hline & $\mathrm{T} 4$ & $5,10 \mathrm{a}$ & $5,94 \mathrm{a}$ & $3,60 \mathrm{a}$ & $1,8 \mathrm{a}$ & $0,02 \mathrm{a}$ & $0,05 \mathrm{a}$ \\
\hline \multirow{3}{*}{$8 . \stackrel{\mathscr{\pi}}{0}$} & T0 & $15,10 \mathrm{a}$ & $15,8 \mathrm{a}$ & $26,2 \mathrm{a}$ & $2,4 \mathrm{a}$ & $0,09 \mathrm{a}$ & $0,29 \mathrm{a}$ \\
\hline & T3 & $13,40 \mathrm{a}$ & $16,7 \mathrm{a}$ & $27,4 \mathrm{a}$ & $3,2 \mathrm{a}$ & $0,10 \mathrm{a}$ & $0,27 \mathrm{a}$ \\
\hline & $\mathrm{T} 4$ & $13,10 \mathrm{a}$ & $17,0 \mathrm{a}$ & $28,0 \mathrm{a}$ & $3,2 \mathrm{a}$ & $0,10 \mathrm{a}$ & $0,27 \mathrm{a}$ \\
\hline \multirow{3}{*}{ 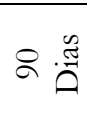 } & T0 & $20,20 \mathrm{a}$ & $31,9 \mathrm{a}$ & $56,4 \mathrm{a}$ & $4,8 \mathrm{a}$ & $0,44 \mathrm{a}$ & $1,49 \mathrm{a}$ \\
\hline & T3 & $23,10 \mathrm{a}$ & $36,6 \mathrm{a}$ & $69,8 \mathrm{a}$ & $5,2 \mathrm{a}$ & $0,50 \mathrm{a}$ & $1,52 \mathrm{a}$ \\
\hline & $\mathrm{T} 4$ & $22,20 \mathrm{a}$ & $34,4 \mathrm{a}$ & $65,6 \mathrm{a}$ & $5,6 \mathrm{a}$ & 0,46 a & $1,77 \mathrm{a}$ \\
\hline
\end{tabular}

*Médias seguidas pela mesma letra, na coluna, não diferem entre si ao nível de 5\% de significância pelo Teste de Tukey. CR: comprimento de raiz; CPA: comprimento da parte aérea; NF: número de folhas; MFPA: massa fresca da parte aérea; MFR: massa fresca da raiz; DC: diâmetro do coleto; MSR: massa seca da raiz; MSPA: massa seca da parte aérea. T0: 100\% Substrato; T3: $25 \%$ lodo de esgoto $+75 \%$ substrato e T4: $50 \%$ lodo de esgoto $+50 \%$ substrato.

Observa-se que aos 30 dias após replantio, apenas o parâmetro fitométrico comprimento da parte aérea (CPA) para as mudas de Angico apresentou diferença estatística entre os tratamentos. Verifica-se que o tratamento T0 diferiu estatisticamente dos tratamentos T3 e T4, os quais não diferiram entre si e 
apresentaram as melhores médias. Segundo Gomes et al. (2013), tal resultado está associado ao maior teor de $\mathrm{N}$ em relação ao substrato comercial (Tabela 1), essencial para o desenvolvimento inicial das plantas.

Além disso, observa-se na Tabela 1 , que o lodo de esgoto apresenta elevada concentração de zinco, o qual é considerado um elemento de grande importância para as plantas, participando como componente de um grande número de enzimas, no metabolismo de carboidratos, proteínas e fosfatos, além da formação da estrutura das auxinas, metabolismo dos fenóis e aumento do tamanho e multiplicação celular (BORKERT, 1989; TAIZ; ZEIGER, 2004).

Caldeira et al. (2013), também descreveram resultados similares ao presente estudo, constatando maiores médias de altura para mudas de eucalipto nos tratamentos com $60 \%, 40 \%$ e $20 \%$ de lodo de esgoto associado à vermiculita. Nóbrega et al. (2007), também observaram tendência de aumento nos valores desse parâmetro para a espécie Schinus terebynthifolius, a partir da primeira dose de lodo de esgoto $(20 \%)$.

Corroboram ainda com o presente estudo, os resultados apresentados por Faustino et al. (2005), os quais testaram as seguintes proporções de lodo com solo: $0 \%, 25 \%, 50 \%, 75 \%$ e uma mistura de $25 \%$ de lodo com $25 \%$ de pó de coco no desenvolvimento de mudas de Senna siamea Lam. Os autores observaram que os substratos mais ricos em composto orgânico propiciaram melhor crescimento das mudas, com boa formação do sistema radicular e melhor balanço nutricional, com melhor resultado associado ao substrato composto por $50 \%$ de lodo.

O parâmetro comprimento da parte aérea, segundo Mexal e Lands (1990), fornece uma excelente estimativa da predição do crescimento inicial da mudas no campo, sendo tecnicamente, aceita como uma boa medida do potencial de desempenho das mudas. Gomes et al. (2002) também destacam que a altura da parte aérea, quando avaliada isoladamente pode ser utilizada como indicativo da qualidade das mudas.

Analisando os demais parâmetros verifica-se que não houve diferença estatística significativa aos 30 dias após replantio (DAR), assim como aos 60 e 90 DAR para nenhuma das espécies avaliadas. Apesar disso, ao final da avaliação (90 DAR), é possível verificar que alguns parâmetros apresentaram resultados mais satisfatórios em alguns tratamentos, embora sem diferença estatística. Este avaliação é importante, pois o desenvolvimento das mudas na fase que antecede seu transplante é extremamente importante para garantir o sucesso a campo.
Dentre tais parâmetros, o comprimento de raiz (CR), segundo Hartmann, Kester e Davies Junior (1990) é influenciado pela composição do substrato, sendo que os principais efeitos desta influência manifestam-se no crescimento da parte aérea. Esta afirmativa é corroborada ao se analisar os resultados apresentados na Tabela 2, aos 90 dias, em que o melhor resultado para este parâmetro está associado ao tratamento T3, o qual apresentou assim, como o tratamento T4, as maiores médias para comprimento da parte aérea, evidenciando a relação existente.

Outro aspecto importante da avaliação do desenvolvimento de mudas é o diâmetro do coleto (DC). Analisando a Tabela 2 aos 90 dias, observa-se que os tratamentos T3 e T4 apresentaram as maiores médias, embora sem diferença estatística. $\mathrm{O}$ diâmetro do coleto é uma característica facilmente mensurável, considerada por muitos pesquisadores como uma das mais importantes características para estimar a sobrevivência após o plantio de mudas de diferentes espécies florestais (GOMES et al., 2002; SOUZA; OLIVEIRA; LIMA, 2006). Tal característica é utilizada para auxiliar na definição das doses de fertilizantes a serem aplicados na produção de mudas e para avaliação da capacidade de sobrevivência em campo, já que mudas de maior incremento em diâmetro possuem maior capacidade de formação e de crescimento de novas raízes (SOUZA; OLIVEIRA;LIMA, 2006).

O parâmetro fitométrico massa seca da parte aérea (MSPA) por sua vez, é uma importante característica de avaliação, pois indica a rusticidade das mudas (CALDEIRA et al. 2008a, 2008b). No experimento em estudo, a maior produção de MSPA foi verificada para os tratamentos T3 e T4, respectivamente, nas duas espécies estudadas, embora não tenham sido observadas diferenças em relação ao substrato comercial. O resultado obtido no tratamento (T3) correlaciona com as médias superiores encontradas para altura no mesmo tratamento aos 90 DAR, mostrando a relação existente entre o parâmetro altura e a produção de massa seca da parte aérea. Segundo Gomes e Paiva (2006), existe uma relação entre os fatores que influenciam no crescimento em altura e o ganho de massa de matéria seca, podendo também estar relacionado com a maior disponibilidade de $\mathrm{N}$, Ca e com o pH, nos substratos com lodo que proporcionaram melhores crescimentos das características avaliadas (Tabela 1).

Ao avaliar o desenvolvimento de mudas, alguns autores, reconhecem o parâmetro massa seca de raízes (MSR) como uma das melhores características para se estimar a sobrevivência e o crescimento inicial das mudas no campo (GOMES et al., 2002; 
CALDEIRA et al., 2008a, 2008b). De maneira geral, o lodo de esgoto associado ao substrato comercial, exerceu tendência positiva no aumento da produção de MSR, conforme verificado na Tabela 2. O tratamento T3 $(25 \%$ lodo de esgoto $+75 \%$ substrato, apresentou a maior média aos 90 DAR, seguido do tratamento T4 $(50 \%$ lodo $+50 \%$ substrato), embora sem diferença estatística em relação ao substrato comercial. Gomes et al. (2013), relatam em seu estudo utilizando lodo de esgoto, que doses crescentes de lodo no substrato, produziram efeito positivo no acúmulo de massa seca de raízes. No entanto, em proporções elevadas de lodo de esgoto, não foi obtido incremento significativo deste parâmetro, provavelmente em razão das alterações indesejáveis das características físicas (macro e microporosidade) que o uso de altas concentrações de lodo de esgoto pode proporcionar ao substrato (TRAZZI; CALDEIRA; COLOMBI, 2010), sendo esta uma provável causa do resultado obtido para o tratamento T4.

Ainda analisando a Tabela 2, verifica-se que aos 90 dias o parâmetro fitométrico, número de folhas (NF) apresentou melhores médias para o tratamento T3, nas duas espécies estudadas, embora sem diferença significativa em relação aos demais tratamentos. Realizando uma análise conjunta dos parâmetros é possível constatar a inter-relação entre eles, ou seja, os maiores valores de número de folhas e comprimento de raiz refletiram diretamente sobre a massa seca da parte aérea, diâmetro do coleto e massa seca da raiz, para este tratamento.

Faria et al. (2013), verificaram o potencial do uso do lodo de esgoto, palha de café in natura e esterco bovino na formulação de substratos para a produção de mudas de Senna alata e concluíram que a adição do composto orgânico resultou em valores superiores dos parâmetros comprimento da parte aérea (CPA), diâmetro do coleto (DC), massa seca da parte aérea (MSPA) e massa seca radicular (MSR), recomendando o uso dos substratos formulados com $60 \%$ lodo de esgoto $+40 \%$ do composto orgânico, ou $20 \%$ lodo de esgoto $+80 \%$ do composto orgânico.

Os resultados acima descritos permitem verificar que embora sem diferença estatística significativa, os tratamentos T3 e T4 apresentaram médias superiores na maioria dos parâmetros avaliados em relação ao substrato comercial aos 90 DAR. Esse resultado indica a possibilidade do uso do lodo de esgoto na produção de mudas, considerando que não houve diferença em relação ao substrato comercializado, sendo, portanto, uma alternativa viável para a disposição final desses resíduos, tendo em vista a economia de fertilizantes.
Esse resultado vem de encontro com Trigueiro e Guerrini (2014), os quais avaliaram o desenvolvimento de mudas de Aroeira-pimenteira produzidas com substratos contendo lodo de esgoto como fonte de matéria orgânica e de nutrientes, concluindo que o uso de lodo de esgoto em viveiros florestais, na composição de substratos, é alternativa viável para a disposição final desse resíduo.

Outro aspecto importante a ser abordado, refere-se à análise isolada das espécies, permitindo verificar que as médias obtidas aos 90 dias para o Cedro foram maiores em comparação as do Angico, sugerindo que o Cedro apresenta maior adaptabilidade ao uso do lodo de esgoto.

Salienta-se ainda, que o uso do lodo de esgoto na agricultura ainda é bastante restritivo considerando seu potencial poluidor. Em virtude disso foi publicado em agosto de 2006 pelo Conselho Nacional do Meio Ambiente (CONAMA), por meio da Resolução no 375, critérios e procedimentos, para o uso agrícola de lodos de esgoto gerados em estações de tratamento de esgoto sanitário e seus produtos derivados. A resolução determina as concentrações limite de metais, as cargas cumulativas máximas permitidas para a aplicação em solos agrícolas, presença de patógenos e as espécies para as quais o seu uso é recomendado (BRASIL, 2006). Com base nisso nas concentrações de metais pesados, verifica-se na Tabela 1 , que as concentrações de $\mathrm{Cu}\left(114 \mathrm{mg} \mathrm{kg}^{-1}\right)$ e $\mathrm{Zn}\left(283 \mathrm{mg} \mathrm{kg}^{-1}\right)$ não seriam limitantes para seu uso na produção de mudas na condição testada, uma vez que encontram-se abaixo dos valores de 1500 e $2800 \mathrm{mg} \mathrm{kg}^{-1}$, respectivamente, estabelecidos pela resolução.

\section{CONCLUSÕES}

O uso de cama de aviário nas condições e proporções testadas não é adequada para a produção de mudas de Cedro e Angico. No entanto, ressalta-se a importância, da realização de trabalhos posteriores, testando doses menores de cama de aviário na produção das mudas destas espécies, especialmente utilizando cama de aves previamente compostada.

O uso de lodo de esgoto, como componente de substratos, é uma alternativa viável para a disposição final desse resíduo, substituindo satisfatoriamente $\mathrm{o}$ substrato comercial.

\section{AGRADECIMENTOS}

Universidade Tecnológica Federal do Paraná (UTFPR) Câmpus Francisco Beltrão e Secretaria 
Municipal de Meio Ambiente de Francisco Beltrão (SEMA).

\section{REFERÊNCIAS}

BORKERT, C. M. Micronutrientes na planta. In: BÜLL, L. T.; ROSOLEM, C. A. Interpretação de análise química de solo e planta para fins de adubação. Botucatu, SP: Fundação de Estudos e Pesquisas Agrícolas e Florestais, 1989. cap.16, p.309-329.

BRASIL. Resolução No. 375, de 29 de agosto de 2006. Diário Oficial [da] República Federativa do Brasil, Brasília, n. 167, p. 141-146, 30 ago. 2006. Seção 1.

BRUGNARA, E. C. Cama de aviário em substratos para mudas de maracujazeiro-amarelo. Revista Brasileira de Agroecologia, v. 9, n. 3, p. 21-30, 2014. Disponível em: http://abaagroecologia.org.br/revistas/index.php/rbag roecologia/article/view/15270. Acesso em: 06 abr. 2017.

CALDEIRA, M. V. W. et al. Uso do resíduo do algodão no substrato para produção de mudas florestais. Revista Acadêmica: Ciências Agrárias e Ambientais, v. 6, n.2, p. 191-202, abr./jun. 2008a. Disponível

em: https://periodicos.pucpr.br/index.php/cienciaanimal/ article/view/10472/9869. Acesso em: 04 fev. 2017

CALDEIRA, M. V. et al. Lodo de esgoto e vermiculita na produção de mudas de eucalipto. Pesquisa Agropecuária Tropical, v. 43, n. 2, p. 155-163, abr./jun. 2013.

$$
\text { Disponível }
$$

http://www.scielo.br/pdf/pat/v43n2/v43n2a02.pdf

Acesso em: 12 dez. 2016.

CALDEIRA, M. V. W. et al. Lodo de esgoto como componente de substrato para produção demudas de Acacia mangium Wild. Comunicata Scientiae, v. 5, n. 1, p. 34-43, jan./mar. 2014. Disponível em: file:///C:/Users/User/Downloads/Dialnet

LodoDeEsgotoComoComponenteDeSubstratoParaPro ducaoD-5022030.pdf. Acesso em: 04 fev. 2017.

CALDEIRA, M. V. W. et al. Composto orgânico na produção de mudas de aroeira vermelha. Scientia Agraria, v. 9, n.1, p. 27-33, 2008b. Disponível em: file://C:/Users/User/Downloads/9898-41443-1PB.pdf. Acesso em: 12 fev. 2017.
CALDEIRA, M. V. W. et al. Principais tipos e componentes de substratos para produção de mudas de espécies florestais. In: CALDEIRA, M. V. W. et al. Contexto e perspectivas da aérea florestal no Brasil. Visconde do Rio Branco, MG: Suprema, 2011a. v. 1, p. 51-100.

CALDEIRA, M. V. W. et al. Propriedades de substratos para produção de mudas florestais. In: CALDEIRA, M.V.W. et al. Contexto e perspectivas da área florestal no Brasil. Visconde do Rio Branco, MG: Suprema, 2011b. v. 1, p. 142-160.

CARDOSO, A. L. S. P. et al. Avaliação da qualidade sanitária de incubatório por meio de placas de sedimentação. Arquivos do Instituto Biológico, v. 76, n. 2, p. 279-283, abr./jun. 2009. Disponível em: http://www.biologico.sp.gov.br/docs/arq/v76 2/card oso.pdf. Acesso em: 12 out. 2016.

CARVALHO, J. E. U. et al. Efeito de doses percentuais de cama de frango na produção de mudas de Abieiro. Comunicado Técnico n. 90, Belém: Embrapa Amazônia Oriental, p. 1-3, 2004. Disponível em:

https://www.infoteca.cnptia.embrapa.br/bitstream/do c/407131/1/com.tec.90.pdf. Acesso em: 19 abr. 2017.

FARIA, J. C. T. et al. Uso de resíduos orgânicos na produção de mudas de Senna alata (L.) Roxb. Ecologia e Nutrição Florestal, v. 1, n. 3, p. 133-146, set./dez. $2013 . \quad$ Disponível em: https://periodicos.ufsm.br/enflo/article/view/14754/ pdf. Acesso em: 24 mar.2017.

FAUSTINO, R. et al. Lodo de esgoto como substrato para produção de mudas de Senna siamea Lam. Revista Brasileira Engenharia Agrícola Ambiental, v.9, suplemento, p. 278-282, 2005. Disponível em: http://www.agriambi.com.br/revista/suplemento/inde

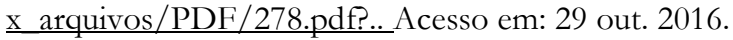

GOMES, D. R. et al. Lodo de esgoto como substrato para a produção de mudas de Tectona grandis L. Cerne, v. 19, n. 1, p. 123-131, jan./mar. 2013. Disponível em: http://www.scielo.br/pdf/cerne/v19n1/15.pdf. Acesso em: 19 dez. 2016.

GOMES, J. M. et al. Parâmetros morfológicos na avaliação da qualidade de mudas de Eucalyptus grandis. Revista Árvore, v. 26, n. 6, p. 655-664, 2002. Disponível em: http://www.scielo.br/pdf/rarv/v26n6/a02v26n6.pdf. Acesso em: 04 abr. 2017. 
GOMES, J. M.; PAIVA, H. N. Viveiros florestais: propagação sexuada. 3. ed. Viçosa, MG: UFV, 2006.

HARTMANN, H. T.; KESTER, D. E.; DAVIES, F.T. Plant Propagation: Principles and Practices. 5 ed. New York: Prentice Hall, 1990.

HUANG, G. F. A. et al. Effect of C/N on composting of pig manure with sawdust. Waste Management, v. 24, n. 8, p. 805-813. 2004. Disponível em: http://www.sciencedirect.com/science/article/pii/S09 56053X04000753. Acesso em: 08 mar. 2017.

KIEHL, E. J. Fertilizantes orgânicos: determinações analíticas. Piracicaba, SP: Agronômica Ceres, 1985.

LIMA, C. J. G. S. et al. Avaliação de diferentes bandejas e substratos orgânicos na produção de mudas de tomate cereja. Ciência Agronômica, v. 40, n. 1, p. 123-128, jan./mar. 2009. Disponível em: http://ccarevista.ufc.br/seer/index.php/ccarevista/arti cle/view/413/309. Acesso em: 03 fev. 2017.

MEXAL, J. L.; LANDS, T. D. Target seedling concepts: height and diameter. Target Seedling Symposium, Meeting Of The Western Forest Nursery Associations, General Technical Report RM- 200, Roseburg. Proceedings... Fort Collins: USDA, Forest Service, p. 17-35, 1990

NÓBREGA, R. S. A. et al. Utilização de biossólido no crescimento inicial de mudas de aroeira (Schinus terebynthifolius/Raddi). Revista Árvore, v. 31, n. 2, p. 239-246, mar./abr. 2007. Disponível em: http://www.scielo.br/pdf/rarv/v31n2/a06v31n2.pdf. Acesso em: 06 mar. 2017.

PAULUS, G.; MULLER, A. M.; BARCELLOS, L. A. R. Agroecologia aplicada: Práticas e Métodos para uma agricultura de base ecológica. Porto Alegre, RS: EMATER/RS, 2000. 86p.

QI, X. et al. Grain yield and apparent N recovery efficiency of dry direct-seeded rice under different $\mathrm{N}$ treatments aimed to reduce soil ammonia volatilization. Field Crops Research, v. 134, 138-143, 2012. Disponível em: http://www.sciencedirect.com/science/article/pii/S03 78429012001827. Acesso em 28 nov. 2016.
SCHMITZ, J. A. K.; SOUZA, P. V. D.; KÄMPF, A. N. Propriedades químicas e físicas de substratos de origem mineral e orgânica para o cultivo de mudas em recipientes. Ciência Rural, v. 32, n. 6, p.937-944, 2002. Disponível em: http://www.scielo.br/pdf/cr/v32n6/12737.pdf. Acesso em: 19 mar. 2017.

SOUZA, C. A. M.; OLIVEIRA, R. B.; LIMA, J. S. S. Crescimento em campo de espécies florestais em diferentes condições de adubação. Ciência Florestal, v. 16, n. 3, p. 243-249, 2006. Disponível em: https://periodicos.ufsm.br/cienciaflorestal/article/vie w/1905/1149. Aceso em: 12 abr. 2017.

TAIZ, L.; ZEIGER, E. Fisiologia Vegetal. PortoAalegre, RS: Artmed, 2004.

TRAZZI, P. A.; CALDEIRA, M. V. W.; COLOMBI, R. Avaliação de mudas de Tecoma stans utilizando biossólido e resíduo orgânico. Revista de Agricultura, v. 85, n. 3, p. 218-226, 2010. Disponível em: http://www.fealq.org.br/ojs/index.php/revistadeagric ultura/article/view/2853/pdf 2424. Acesso em: 25 abr. 2017.

TRAZZI, P. A. et al. Estercos de origem animal em substratos para a produção de mudas florestais: atributos físicos e químicos. Scientia Forestalis, v. 40, n. 96, p. 455-462, dez. 2012. Disponível em: http://www.ipef.br/publicacoes/scientia/nr96/cap03. pdf. Acesso em: 11 mar. 2017.

TRIGUEIRO, R. M.; GUERRINI, I. Uso de biossólido como substrato para produção de mudas de eucalipto. Scientia Forestalis, n. 64, p. 150-162, dez. $2003 . \quad$ Disponível em: http://www.ipef.br/publicacoes/scientia/nr64/cap13. pdf. Aceso em: 17 abr. 2017.

TRIGUEIRO, R. M.; GUERRINI, I. A. Utilização de lodo de esgoto na produção de mudas de aroeirapimenteira. Revista Árvore, v. 38, n. 4, p. 657-665, $2014 . \quad$ Disponível em: http://www.scielo.br/pdf/rarv/v38n4/09.pdf. Acesso em: 12 dez. 2016. 